\title{
Extracranial arterial wall volume is increased and shows relationships with vascular MRI measures in idiopathic Parkinson's disease
}

\section{Dol:}

10.1016/j.clineuro.2018.02.013

\section{Document Version}

Accepted author manuscript

Link to publication record in Manchester Research Explorer

Citation for published version (APA):

Ball, S., Al-Bachari, S., Parkes, L. M., Emsley, H. C. A., \& McCollum, C. N. (2018). Extracranial arterial wall volume is increased and shows relationships with vascular MRI measures in idiopathic Parkinson's disease. Clinical Neurology and Neurosurgery, 167, 54-58. https://doi.org/10.1016/j.clineuro.2018.02.013

\section{Published in:}

Clinical Neurology and Neurosurgery

\section{Citing this paper}

Please note that where the full-text provided on Manchester Research Explorer is the Author Accepted Manuscript or Proof version this may differ from the final Published version. If citing, it is advised that you check and use the publisher's definitive version.

\section{General rights}

Copyright and moral rights for the publications made accessible in the Research Explorer are retained by the authors and/or other copyright owners and it is a condition of accessing publications that users recognise and abide by the legal requirements associated with these rights.

\section{Takedown policy}

If you believe that this document breaches copyright please refer to the University of Manchester's Takedown Procedures [http://man.ac.uk/04Y6Bo] or contact uml.scholarlycommunications@manchester.ac.uk providing relevant details, so we can investigate your claim.

\section{OPEN ACCESS}




\title{
Extracranial arterial wall volume is increased and shows relationships with vascular MRI measures in idiopathic Parkinson's disease
}

\author{
Stephen Ball ${ }^{\mathrm{a}}$ \\ Sarah Al-Bachari ${ }^{\mathrm{b}, \mathrm{d}, \mathrm{e}}$ \\ Laura M. Parkes ${ }^{\mathrm{c}, \mathrm{e}}$ \\ Hedley C. A. Emsley ${ }^{\mathrm{d}, \mathrm{f}, \mathrm{g}}$ \\ Charles N. McCollum ${ }^{\mathrm{a}}$
}

a Academic Surgery Unit, Institute of Cardiovascular Sciences, University of Manchester

${ }^{b}$ Department of Neurology, Salford Royal NHS Foundation Trust, Salford, UK

${ }^{c}$ Division of Informatics, Imaging and Data Sciences, School of Health Sciences, Faculty of

Biology, Medicine and Health, University of Manchester, UK

${ }^{\mathrm{d}}$ Faculty of Health and Medicine, Lancaster University, UK

${ }^{\mathrm{e}}$ Division of Neuroscience and Experimental Psychology, School of Biological Sciences,

Faculty of Biology, Medicine and Health, University of Manchester, UK

f Department of Neurology, Royal Preston Hospital, Preston, UK

${ }^{\mathrm{g}}$ Faculty of Biology, Medicine and Health, University of Manchester, UK

\section{Correspondence to:}

\author{
Mr Stephen Ball \\ University Hospital of South Manchester, \\ Academic Surgery Unit, Manchester, UK. \\ Email: stephen.ball@manchester.ac.uk \\ Tel: +44 (0)1612915853 \\ Fax: +44 (0)1612915854
}

\begin{abstract}
Sources of Funding: The sources of funding were the Manchester Surgical Research Trust (Registered Charity No. 702313), the Sydney Driscoll Neuroscience Foundation (Registered Charity No. 1129387), and a local stroke neurology research fund. The funding sources had no involvement in the design, collection or interpretation of the data.
\end{abstract}

\section{Keywords:}

Idiopathic Parkinson's disease; wall volume; cerebral emboli; white matter lesion volume; arterial arrival time. 


\begin{abstract}
Objective

Idiopathic Parkinson's disease (IPD) is the second most common neurodegenerative disorder, often complicated by dementia. Cardiovascular risk factors and spontaneous cerebral emboli (SCE) are strongly associated with Alzheimer's (AD) and vascular dementia (VaD). We measured SCE in the middle cerebral artery and arterial wall volume in the extracranial arteries in patients with IPD and controls, and explored the relationships with structural and physiological MRI brain neurovascular measures.
\end{abstract}

\title{
Patients and Methods
}

Arterial wall volume over $2 \mathrm{~cm}$ of the axillary and internal carotid arteries (ICA) bilaterally was measured by 3-D tomographic ultrasound in 15 IPD patients and 16 age/gender matched controls. SCE were counted by Transcranial Doppler (TCD) using international consensus criteria. Venous to arterial circulation shunting ( $\mathrm{v}-\mathrm{aCS})$, usually through a patent foramen ovale (PFO), was measured using a TCD technique with intravenous microbubble contrast. Structural and physiological MRI brain neurovascular measures, acquired separately, comprised white matter lesion volume (WMLV), cerebral blood flow (CBF) and arterial arrival time (AAT).

\section{Results}

Mean $\left(95 \%\right.$ CI) axillary and ICA wall volume was higher in IPD patients at $523 \mathrm{~mm}^{3}(446$, $600)$ and $455 \mathrm{~mm}^{3}(374,536)$ respectively compared with $412 \mathrm{~mm}^{3}(342,483)$ and $408 \mathrm{~mm}^{3}$ $(362,454)$ in controls being significant for the axillary artery $(p=0.04)$.

Cerebral WMLV was related to mean arterial wall volume for both axillary $(r=0.555$, $p=0.009)$ and ICA $(r=0.559, p=0.026)$ in all participants.

SCE were detected in four IPD patients and three controls $(p=1.00)$. Two IPD patients and three controls were positive for a $\mathrm{V}$-aCS equivalent to PFO $(p=0.477)$.

\section{Conclusion}

Although frequent in $\mathrm{AD}$ and $\mathrm{VaD}$, neither SCE nor v-aCS were associated with IPD. This is the first study to demonstrate arterial wall volume is increased in IPD and relates to WMLV. 


\section{Introduction}

Idiopathic Parkinson's disease (IPD) is the second most common neurodegenerative disorder worldwide after Alzheimer's disease (AD). In the UK, IPD has an overall prevalence of 1 in 500 , but there is a striking increase with age. Pathological hallmarks include progressive degeneration of dopaminergic (DA) neurones projecting from the substantia nigra (SN) to the striatum and intracytoplasmic inclusions called Lewy bodies comprising aggregated forms of the protein $\alpha$-synuclein within surviving SN DA neurones.(1) Clinical diagnosis rests on the cardinal motor features of bradykinesia, rest tremor, rigidity, and postural instability, although IPD causes a number of non-motor features including disturbances of sleep, mood and cognition. Neurodegenerative disorders are increasingly believed to be multifactorial with many factors leading to neuronal death. (2) Accumulating evidence suggests that the neurodegenerative process is also influenced by neurovascular changes which constitute more than simply the presence of comorbid cerebrovascular disease (CVD) as a consequence of ageing. Blood-brain barrier (BBB) damage is implicated in the pathogenesis of IPD, with normal BBB structure and function being dependent on the integrity of the neurovascular unit (NVU), which comprises pericytes, glial cells, neurones and basal lamina, and tightly regulates the blood-brain interface. For example, string vessels comprising collapsed basement membrane lacking endothelium, with no function in circulation, are increased in IPD, suggesting a possible role for cerebral hypoperfusion in the neuronal degeneration of IPD, which needs further investigation.(3)

Studies on the prevalence of CVD in IPD have generated conflicting results with reports of increased, (4-8) decreased (9-11) or unchanged prevalence (12-16), by comparison with controls. Recently, MRI measures of neurovascular status have found prolonged arterial arrival time, thought to be related to age driven structural cerebrovascular changes, in patients with IPD compared to age and cardiovascular risk matched controls. (17)

We have previously demonstrated that cerebral emboli have a role in the pathophysiology of $\mathrm{AD}$ and vascular dementia (VaD), two other common neurodegenerative disorders. (18-23) Cerebral emboli showed similar frequency, and similar association with cognitive decline, in both $\mathrm{AD}$ and $\mathrm{VaD}$, suggesting some commonalities in pathophysiology. This could be mediated via disturbance of the cerebral microcirculation as a result of cerebral microemboli, potentially associated with microglial activation and neuroinflammation. In this study we have investigated cerebral emboli and extracranial arterial wall volume in patients with IPD, 
and explored the relationships with structural and physiological MRI brain neurovascular measures.

\section{Patients and Methods}

Participants enrolled in an MRI study investigating structural and physiological neurovascular measures were invited to participate. These included both patients with IPD and age and gender matched healthy controls. Eligibility criteria for IPD participants were a clinical diagnosis of IPD fulfilling UK Parkinson's disease society brain bank criteria. Exclusion criteria included; Clinical or radiological features suggesting secondary or atypical parkinsonism; Features suggesting vascular parkinsonism; History of TIA or stroke; Other Focal neurological signs; Cognitive dysfunction; Evidence of infection within the previous 6 weeks or the presence of a concomitant inflammatory condition. Local ethical approval was granted and patients underwent written informed consent.

3D tomographic ultrasound (3D t-US) was used to measure arterial wall volume, as an accurate measure for intimal thickness, bilaterally over $2 \mathrm{cms}$ of the axillary and internal carotid arteries (ICA). A magnetically tracked freehand t-us system (Curefab GmbH, Munich, Germany) was attached to a Philips iu22 duplex ultrasound (Philips, Bothwell, USA) to track the transducer orientation and position in time and space. Multi-planar reconstructions (MPR) were computed with an ultrasound volume from the 2D ultrasound frames almost instantly. Firstly, a plain 2D scan was performed in B-Mode to gain a signal and grade stenosis using a combination of grey-scale and velocity. A $2 \mathrm{~cm}$ segment of each artery was then scanned in the transverse plane and the images captured on the 3D software. The proximal $2 \mathrm{cms}$ of the ICA and $2 \mathrm{cms}$ of the axillary artery which produced the clearest images were chosen for analysis. Volume was calculated by two independent observers using manual planimetry. The outer and inner vessel walls were identified and circumscribed for each transverse slice with an inter-slice distance of $1 \mathrm{~mm}$. The volume was then calculated automatically by summing the areas in each slice and multiplying it by the inter-slice distance.

By insonating the middle cerebral artery (MCA) through the transtemporal window, cerebral emboli can be detected and their frequency counted. All patients underwent one hour of continuous transcranial Doppler (TCD) insonation of the middle cerebral artery using a 2MHz pulsed-wave Doppler probe. Patients were observed for any movement or potential artefacts and the data analysed by two observers, blinded to each other's results. The 
international consensus criteria (24) for emboli detection were used, which specify that embolic signals should be transient (lasting $<300$ millisec), at least $3 \mathrm{~dB}$ higher than the background blood flow, unidirectional, within the Doppler spectrum, and accompanied by an audible 'snap', 'chirp', or 'moan'.

The presence of a v-aCS was investigated using an emulsion of air microbubbles in saline as an ultrasound contrast medium following the completion of one hour TCD. The bubble suspension was rapidly injected intravenously under three conditions, each separated by one minute: (i) resting quietly; (ii) coughing repeatedly during injection and for a further $10 \mathrm{sec}$; (iii) performing a standardised Valsalva manoeuvre with $5 \mathrm{sec}$ release after injection. The presence of a v-aCS equivalent to a Patent Foreamen Ovale (PFO) was defined as 15 or more embolic signals with the first within 12 cardiac cycles of contrast administration.

Magnetic resonance imaging was undertaken on a 3T Philips Achieva MRI Scanner. The full MRI methodology has been reported previously. ${ }^{(17)}$ In brief, in this study we used images from: 1) $\mathrm{T}_{2}$-weighted FLAIR (repetition time TR 11s, inversion time TI 2.8s, echo time TE $120 \mathrm{~ms}$ ) from which an estimation of white matter lesion volume (WMLV) (a widely used marker of cerebral small vessel disease) was determined using the lesion segmentation toolbox in SPM8. 2) Arterial spin labelling (ASL), using pulsed labelling and multiphase readout at 4 readout times of 800, 1400, 2000, $2600 \mathrm{~ms}$, TR: $3500 \mathrm{~ms}$; TE 22ms; flip angle 40 degrees with 60 control and label pairs. Voxel-wise fitting to a single blood compartment model enabled quantification of cerebral blood flow (CBF) and arterial arrival time (AAT), the time taken for blood to travel from the labelling slab to the tissue of interest. Whole brain values for CBF and AAT were calculated using a simple threshold mask based on the ASL control images on an individual basis.

Analyses were performed using SPSS version 22. A Generalised Estimating Equation longitudinal regression analysis was used to compare carotid, axillary and temporal artery values between IPD patients and controls. Sets of readings for both the left and right side were obtained from each of 2 observers.

A two-sided 5\% significance level was used throughout the analysis. To assess the relationship between total wall volume and the main outcome variables, namely WMLV, AAT and CBF, Pearson correlation, using Log transformed variables, was used and represented graphically. Linear regression was used when adjusting for variables. Smoking was used as a proxy for gender as no females smoked. Comparisons of the outcome variables 
between patients with IPD and controls were made using independent t-tests and MannWhitney U tests.

Reliability of the two observer values was assessed using a combination of correlational and bland-Altman analysis.

\section{Results}

Fifteen patients with IPD (mean (sd) age 67 (8)) and 16 age and gender matched healthy controls (mean (sd) age 66 (7)) were enrolled. Cardiovascular risk factors did not differ significantly between the two groups (Table 1). Table 2 summarises the outcome variables in the two groups.

\section{Arterial Wall Volume}

As there was good agreement between the two observers, demonstrated by a correlation of $>0.8$ for all but the left ICA (0.74), a mean of the two values was taken for each artery and a mean of left and right for each artery.

Mean $(95 \% \mathrm{CI})$ wall volume of the axillary artery was significantly higher in IPD patients at $522.8 \mathrm{~mm}^{3}(446.0,599.7)$ compared to controls at $412.5 \mathrm{~mm}^{3}(342.2,482.7)$ with a difference of $110.4 \mathrm{~mm}^{3}(6.3,214.5)(\mathrm{p}=0.04)$. Mean wall volume of the ICA was also higher in IPD patients at $455.0 \mathrm{~mm}^{3}(373.9,536.2)$ compared to controls at $407.7 \mathrm{~mm}^{3}(361.58,453.8)$ but this difference of $47.4 \mathrm{~mm}^{3}(-46.0,140.8)$, did not reach statistical significance $(\mathrm{p}=0.32)$.

\section{White Matter Lesion Volume}

Combined analysis of all 31 participants revealed a significant moderate positive correlation between WMLV and mean arterial wall volume for both the ICA $(r=0.436, p=0.026)$ and axillary arteries $(r=0.504, p=0.009)$. (Figure 1) After adjustment for age and smoking the positive correlation remained significant for the axillary artery $(\mathrm{p}=0.009)$ but not for the ICA $(p=0.064)$.

When analysing the subgroups, the correlation between WMLV and mean arterial wall volumes in the IPD group remained positive but weak at 0.142 for the axilla and 0.292 for the ICA. (Figure 2) Neither reached statistical significance before and after adjustment for age and smoking. In the control group, significant positive correlations were reflected for both the ICA $(r=0.651, p=0.012)$ and axillary artery $(r=0.722, p=0.004)$. This significance remained 
for the ICA group $(\mathrm{p}=0.015)$ but was lost for the axillary artery $(\mathrm{p}=0.094)$ when adjusting for age and smoking.

\section{Whole brain Arterial Arrival Time and Cerebral Blood Flow}

Combined analysis of all 31 participants revealed a significant moderate positive correlation between whole brain AAT and mean wall volume of the axillary artery $(r=0.403, p=0.041)$ and a weak non-significant correlation with the ICA $(r=0.236, p=0.245)$. (Figure 3 ) Following adjustment for age and smoking, the significance with the axillary artery wall volume was lost $(\mathrm{p}=0.085)$.

Subgroup analysis revealed weak and moderate correlations between whole brain AAT and mean arterial wall volume of both the ICA $(r=0.238, p=0.457)$ and axillary artery $(r=0.517$, $\mathrm{p}=0.085$ ) in the IPD group. (Figure 4) When adjusted for age and smoking the relationship between whole brain AAT and axillary artery wall volume became significant $(\mathrm{p}=0.022)$. In the control group the correlation with whole brain AAT was weak and non-significant for both the ICA $(r=0.173, p=0.555)$ and axillary artery $(r=0.234, p=0.420)$.

No significant association was observed between mean axillary or ICA wall volume and CBF.

\section{Cerebral Emboli}

TCD monitoring for SCE in the MCA was performed in 12 IPD patients and 12 controls with SCE detected in only 4 (33\%) IPD patients and $3(25 \%)$ healthy controls $(p=1.00)$. Two (17\%) IPD patients and three (25\%) controls were positive for a $\mathrm{v}$-aCS equivalent to PFO $(p=0.477)$; similar to the prevalence of PFO in the adult population.

\section{Discussion}

To our knowledge, this is the first study to investigate extracranial arterial wall volume in idiopathic Parkinson's disease and any potential association with structural and physiological MRI brain neurovascular measures. In addition, we investigated the presence of cerebral emboli and evidence of $\mathrm{v}-\mathrm{aCS}$ in IPD, by comparison with controls.

We have found significantly higher axillary artery wall volume in patients with IPD than in healthy controls. Previously, Rektor et al. reported significantly increased intima-media thickness (IMT) in the common carotid artery (CCA) of patients with IPD compared to controls, concluding that this might suggest a link between generalised atherosclerotic 
disease, of which increased CCA IMT is a known marker, and IPD. (25) A positive correlation was observed between axillary artery wall volume and WMLV in the combined analysis of all participants, and in the analysis of the control group but not in the IPD group, suggesting that there may be differences in underlying pathophysiological factors in healthy ageing and in IPD. Following adjustment for age and smoking, a significant positive correlation was observed between AAT and axillary artery wall volume in the IPD group. This relationship was not seen in the control group. Again, this seems to imply a divergence in underlying pathophysiology.

The question of whether there is any causal relationship between atherosclerotic disease, or between conventional cerebrovascular disease (CVD), and IPD, is unclear. It remains possible that CVD represents a co-morbidity alongside a predominantly age-related neurodegenerative disorder. However, the present observations of increased axillary artery wall volume, and the suggestion of a relationship between axillary artery wall volume and AAT does merit further examination.

Recent findings of alterations in physiological neurovascular measures in IPD - including our own observations of prolonged cerebral AAT, are currently attributed to structural vascular changes such as increased vessel tortuosity, increased rarefaction and arteriolar wall damage, so any potential new insights into novel markers of extracranial arterial changes in IPD, as in the present study, are valuable.(17) Previously we have reported a higher prevalence of radiological and clinical cerebrovascular disease in patients with IPD compared to controls.(26) Emerging data indicate that over $60 \%$ of patients with recent onset IPD have high or medium vascular risk, which is associated with a worse motor and cognitive phenotype. Statins are underused, representing a missed opportunity for vascular secondary prevention.(27) Improved recognition of the burden of systemic vascular changes in IPD, how this may interact with the neurodegenerative process and treatment response, as well as provide opportunities for treatment, is needed.

There is an abundance of literature concerning the aetiology of white matter lesions and their involvement in ageing and in neurological disease, especially dementia.(28-35) It has to be remembered that the pathophysiology of WMLs is unclear and could be multifactorial. The present study found a significant correlation between axillary artery wall volume and WMLV which persisted following adjustment for age and smoking. Our own recent data suggest differences in WML burden between IPD motor phenotypes, with an apparently greater 
burden in patients with the more severe postural instability and gait disorder pattern, and with greater cognitive impairment.(36) The lack of association of ICA wall volume and WMLs in the current study is perhaps surprising given the axillary artery findings, but nonetheless, a lack of association has been reported before.(37) This is likely consistent with the fact that most WMLs are probably not due to atherothromboemboli, and the current finding of axillary artery changes is more indicative of more widespread changes in the vasculature with ageing, including in IPD.

With respect to the TCD findings in the present study, the results do contrast with our findings in $\mathrm{AD}$ and $\mathrm{VaD}$, where an association was observed with spontaneous and paradoxical cerebral emboli. Again, this would argue against a significant role for cerebral emboli as part of the neurovascular process in IPD, although it is acknowledged that our negative finding may be influenced by our small sample size.

This present study was relatively small, which did not afford an opportunity to explore the relationships with different IPD phenotypes, including motor phenotypes and non-motor symptoms such as cognitive impairment and dementia. Large, longitudinal studies of clinical and imaging measures of the extracranial and intracranial vasculature, including the microvasculature, will be required in order to advance our knowledge in this area. However, our results provide some indication that extracranial arterial wall volume may correlate with intracranial small vessel disease, including in patients with IPD.

\section{Conflicts of interest: None}

Acknowledgements: None 


\section{$\underline{\text { References: }}$}

1. Weiss N, Miller F, Cazaubon S, Couraud PO. The blood-brain barrier in brain homeostasis and neurological diseases. Biochimica et biophysica acta. 2009;1788(4):842-57. Epub 2008/12/09.

2. Chung YC, Ko HW, Bok E, Park ES, Huh SH, Nam JH, et al. The role of neuroinflammation on the pathogenesis of Parkinson's disease. BMB reports. 2010;43(4):225-32. Epub 2010/04/29.

3. Yang P, Pavlovic D, Waldvogel H, Dragunow M, Synek B, Turner C, et al. String Vessel Formation is Increased in the Brain of Parkinson Disease. Journal of Parkinson's disease. 2015;5(4):821-36. Epub 2015/10/08.

4. Gorell JM, Johnson CC, Rybicki BA. Parkinson's disease and its comorbid disorders: an analysis of Michigan mortality data, 1970 to 1990. Neurology. 1994;44(10):1865-8. Epub 1994/10/01.

5. Ben-Shlomo Y, Marmot MG. Survival and cause of death in a cohort of patients with parkinsonism: possible clues to aetiology? Journal of neurology, neurosurgery, and psychiatry. 1995;58(3):293-9. Epub 1995/03/01.

6. Becker C, Jick SS, Meier CR. Risk of stroke in patients with idiopathic Parkinson disease. Parkinsonism \& related disorders. 2010;16(1):31-5. Epub 2009/07/31.

7. Piccini P, Pavese N, Canapicchi R, Paoli C, Del Dotto P, Puglioli M, et al. White matter hyperintensities in Parkinson's disease. Clinical correlations. Archives of neurology. 1995;52(2):1914. Epub 1995/02/01.

8. Gattellaro G, Minati L, Grisoli M, Mariani C, Carella F, Osio M, et al. White matter involvement in idiopathic Parkinson disease: a diffusion tensor imaging study. AJNR American journal of neuroradiology. 2009;30(6):1222-6. Epub 2009/04/04.

9. Jellinger KA. Prevalence of vascular lesions in dementia with Lewy bodies. A postmortem study. Journal of neural transmission. 2003;110(7):771-8. Epub 2003/06/18.

10. Struck LK, Rodnitzky RL, Dobson JK. Stroke and its modification in Parkinson's disease. Stroke; a journal of cerebral circulation. 1990;21(10):1395-9. Epub 1990/10/01.

11. Nataraj A, Rajput AH. Parkinson's disease, stroke, and related epidemiology. Movement disorders : official journal of the Movement Disorder Society. 2005;20(11):1476-80. Epub 2005/07/23.

12. Mastaglia FL, Johnsen RD, Kakulas BA. Prevalence of stroke in Parkinson's disease: a postmortem study. Movement disorders : official journal of the Movement Disorder Society. 2002;17(4):772-4. Epub 2002/09/05.

13. Jellinger KA. Prevalence of cerebrovascular lesions in Parkinson's disease. A postmortem study. Acta neuropathologica. 2003;105(5):415-9. Epub 2003/04/05.

14. Ghebremedhin $\mathrm{E}$, Rosenberger A, Rub U, Vuksic M, Berhe T, Bickeboller $\mathrm{H}$, et al. Inverse relationship between cerebrovascular lesions and severity of lewy body pathology in patients with lewy body diseases. Journal of neuropathology and experimental neurology. 2010;69(5):442-8. Epub 2010/04/27.

15. Levine RL, Jones JC, Bee N. Stroke and Parkinson's disease. Stroke; a journal of cerebral circulation. 1992;23(6):839-42. Epub 1992/06/01.

16. Beyer MK, Aarsland D, Greve OJ, Larsen JP. Visual rating of white matter hyperintensities in Parkinson's disease. Movement disorders : official journal of the Movement Disorder Society. 2006;21(2):223-9. Epub 2005/09/15.

17. Al-Bachari S, Parkes LM, Vidyasagar R, Hanby MF, Tharaken V, Leroi I, et al. Arterial spin labelling reveals prolonged arterial arrival time in idiopathic Parkinson's disease. Neurolmage Clinical. 2014;6:1-8. Epub 2014/11/08.

18. Purandare N, Burns A, Daly KJ, Hardicre J, Morris J, Macfarlane G, et al. Cerebral emboli as a potential cause of Alzheimer's disease and vascular dementia: case-control study. Bmj. 2006;332(7550):1119-24. Epub 2006/05/02. 
19. Purandare N, Burns A, Morris J, Perry EP, Wren J, McCollum C. Association of cerebral emboli with accelerated cognitive deterioration in Alzheimer's disease and vascular dementia. The American journal of psychiatry. 2012;169(3):300-8. Epub 2011/12/24.

20. Voshaar RC, Purandare N, Hardicre J, McCollum C, Burns A. Asymptomatic spontaneous cerebral emboli and cognitive decline in a cohort of older people: a prospective study. International journal of geriatric psychiatry. 2007;22(8):794-800. Epub 2006/12/29.

21. Purandare N, Voshaar RC, Morris J, Byrne JE, Wren J, Heller RF, et al. Asymptomatic spontaneous cerebral emboli predict cognitive and functional decline in dementia. Biological psychiatry. 2007;62(4):339-44. Epub 2007/05/29.

22. Purandare N, Oude Voshaar RC, McCollum C, Jackson A, Burns A. Paradoxical embolisation and cerebral white matter lesions in dementia. The British journal of radiology. 2008;81(961):30-4. Epub 2007/11/14.

23. Oude Voshaar RC, Purandare N, Hardicre J, McCollum C, Burns A. Asymptomatic spontaneous cerebral emboli and mood in a cohort of older people: a prospective study. The American journal of geriatric psychiatry : official journal of the American Association for Geriatric Psychiatry. 2007;15(12):1057-60. Epub 2007/12/07.

24. Basic identification criteria of Doppler microembolic signals. Consensus Committee of the Ninth International Cerebral Hemodynamic Symposium. Stroke; a journal of cerebral circulation. 1995;26(6):1123. Epub 1995/06/01.

25. Rektor I, Goldemund D, Sheardova K, Rektorova I, Michalkova Z, Dufek M. Vascular pathology in patients with idiopathic Parkinson's disease. Parkinsonism \& related disorders. 2009;15(1):24-9. Epub 2008/04/12.

26. Patel M, Coutinho C, Emsley HC. Prevalence of radiological and clinical cerebrovascular disease in idiopathic Parkinson's disease. Clin Neurol Neurosurg. 2011;113(10):830-4. Epub 2011/06/22.

27. Swallow DM, Lawton MA, Grosset KA, Malek N, Klein J, Baig F, et al. Statins are underused in recent-onset Parkinson's disease with increased vascular risk: findings from the UK Tracking Parkinson's and Oxford Parkinson's Disease Centre (OPDC) discovery cohorts. Journal of neurology, neurosurgery, and psychiatry. 2016;87(11):1183-90. Epub 2016/09/28.

28. Debette S, Beiser A, DeCarli C, Au R, Himali JJ, Kelly-Hayes M, et al. Association of MRI markers of vascular brain injury with incident stroke, mild cognitive impairment, dementia, and mortality: the Framingham Offspring Study. Stroke; a journal of cerebral circulation. 2010;41(4):6006. Epub 2010/02/20.

29. Pantoni L, Garcia JH. Pathogenesis of leukoaraiosis a review. Stroke; a journal of cerebral circulation. 1997;28(3):652-9.

30. Van Swieten J, Van den Hout J, Van Ketel B, Hijdra A, Wokke J, Van Gijn J. Periventricular lesions in the white matter on magnetic resonance imaging in the elderly. Brain. 1991;114(2):761-74. 31. Yoshita M, Fletcher E, Harvey D, Ortega M, Martinez O, Mungas D, et al. Extent and distribution of white matter hyperintensities in normal aging, $\mathrm{MCl}$, and $\mathrm{AD}$. Neurology. 2006;67(12):2192-8.

32. Zlokovic BV. Neurovascular mechanisms of Alzheimer's neurodegeneration. Trends in neurosciences. 2005;28(4):202-8.

33. Kandiah N, Goh O, Mak E, Marmin M, Ng A. Carotid stenosis: a risk factor for cerebral whitematter disease. Journal of stroke and cerebrovascular diseases : the official journal of National Stroke Association. 2014;23(1):136-9. Epub 2012/12/26.

34. Altaf N, Daniels L, Morgan PS, Lowe J, Gladman J, MacSweeney ST, et al. Cerebral white matter hyperintense lesions are associated with unstable carotid plaques. European journal of vascular and endovascular surgery : the official journal of the European Society for Vascular Surgery. 2006;31(1):8-13. Epub 2005/10/18. 
35. Conklin J, Fierstra J, Crawley AP, Han JS, Poublanc J, Silver FL, et al. Mapping white matter diffusion and cerebrovascular reactivity in carotid occlusive disease. Neurology. 2011;77(5):431-8. Epub 2011/07/22.

36. Al-Bachari S VR, Emsley HC, Parkes LM. Structural and physiological neurovascular changes in idiopathic Parkinson's disease and it's clinical phenotypes. Journal of cerebral blood flow and metabolism : official journal of the International Society of Cerebral Blood Flow and Metabolism. 2017.

37. Potter GM, Doubal FN, Jackson CA, Sudlow CL, Dennis MS, Wardlaw JM. Lack of association of white matter lesions with ipsilateral carotid artery stenosis. Cerebrovascular diseases.

2012;33(4):378-84. Epub 2012/03/22. 
Table 1: Cardiovascular risk factors between the two groups

\begin{tabular}{cccc}
\hline CV Risk Factor & IPD & Control & P-value \\
\hline Hypertension & 6 & 6 & 0.462 \\
Diabetes & 1 & 2 & 0.619 \\
Hypercholesterolaemia & 3 & 9 & 0.098 \\
Ischaemic Heart Disease & 2 & 2 & 0.660
\end{tabular}

Table demonstrating no difference between the two groups with regards cardiovascular risk factors. 
Table 2: Comparison of outcome variables between the two groups

\begin{tabular}{cccc}
\hline & IPD & Control & P-value \\
\hline $\begin{array}{c}\text { Mean ICA (sd) Wall } \\
\text { Volume }\end{array}$ & $455(97.1)$ & $407.4(166)$ & 0.32 \\
$\begin{array}{c}\text { Mean (sd) Axillary Wall } \\
\text { Volume }\end{array}$ & $522.8(157.1)$ & $412.5(148)$ & 0.04 \\
Mean (sd) WMLV & $5.29(6.2)$ & $6.49(11.3)$ & 0.410 \\
Mean (sd) AAT & $1491(137.9)$ & $1421.6(152.6)$ & 0.227 \\
Mean (sd) CBF & $45.8(8.5)$ & $46.2(5.3)$ & 0.797 \\
& & & \\
+ ve Emboli (n=12) & 4 & 3 & $/ /$ \\
\hline +ve V-acs (n=12) & 2 & 3 & \\
\hline
\end{tabular}

Table demonstrating that the mean wall volume of both the internal carotid artery (ICA) and axillary artery is increased in patients with idiopathic parkinsons disease (IPD) and significantly so for axillary wall volume. 


\section{Figure 1: Scattergram demonstrating relationship between man arterial wall volume}

and LogWMLV and LogAAT in all patients

Figure 1: Scatter plots demonstrating the relationship between mean arterial wall volume $\left(\mathrm{mm}^{3}\right)$ and white matter lesion volume (WMLV) and arterial arrival time (AAT). There is a significant moderate correlation between WMLV and both mean internal carotid artery (ICA) wall volume (A) and mean axillary wall volume (B). There was no association between AAT and ICA mean wall volume $(\mathrm{C})$ but a moderate significant association between with mean axillary wall volume (D). 


\section{Figure 2: Scattergrams demonstrating the relationship between mean artery wall}

volume and LogWMLV and LogAAT in IPD patients

Figure 2: Scatter plots demonstrating a lack of relationship between mean arterial wall volumes of both the internal carotid artery (ICA) and axillary artery with white matter lesion volume $(\mathrm{WMLV})(\mathrm{A}+\mathrm{B})$ and arterial arrival time $(\mathrm{AAT})(\mathrm{C}+\mathrm{D})$ in patients with idiopathic parkinsons disease (IPD). 

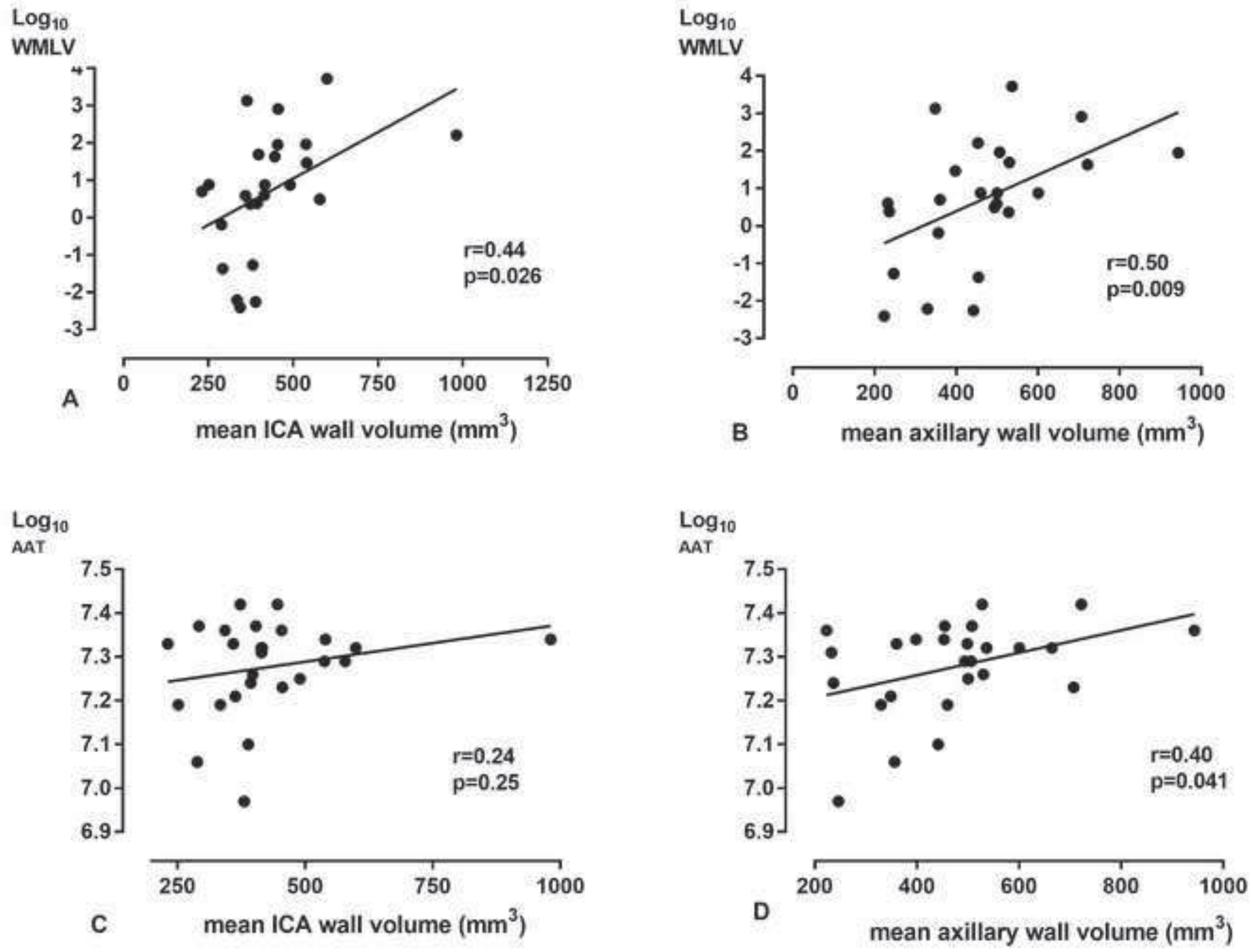


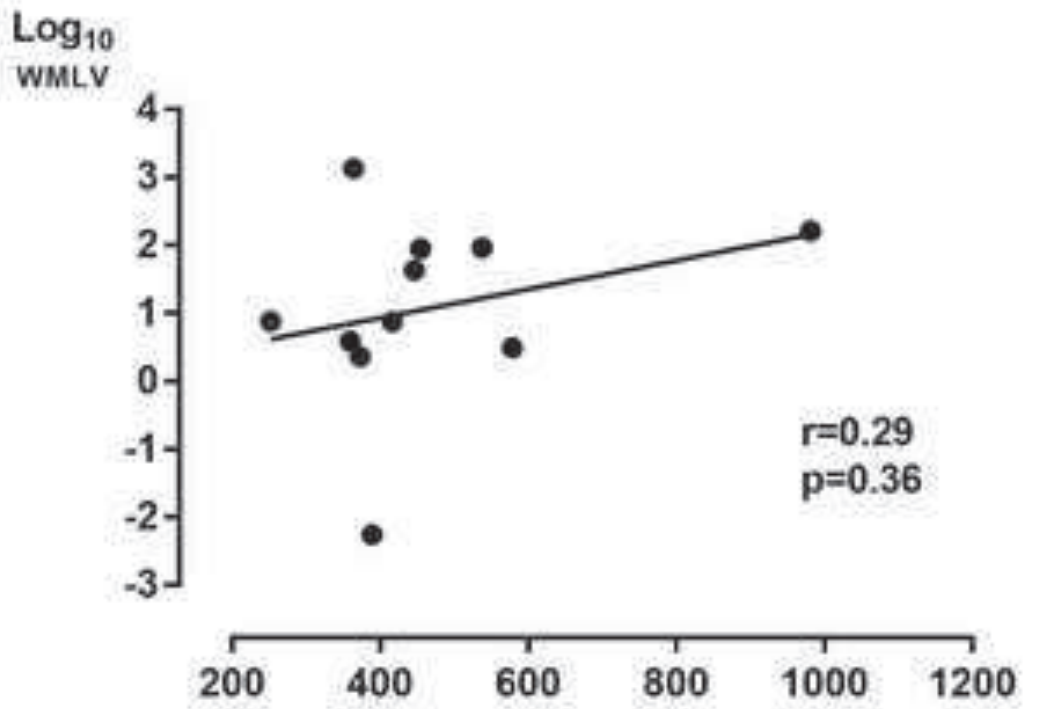

A mean ICA wall volume $\left(\mathrm{mm}^{3}\right)$

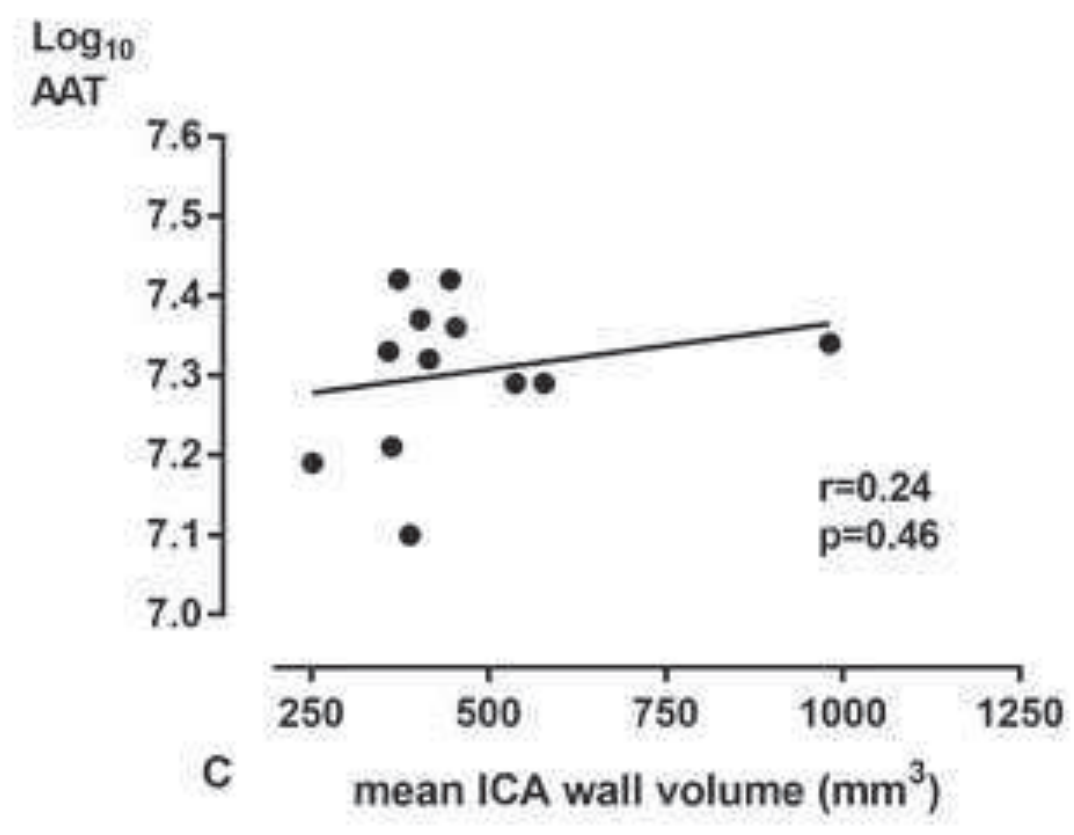

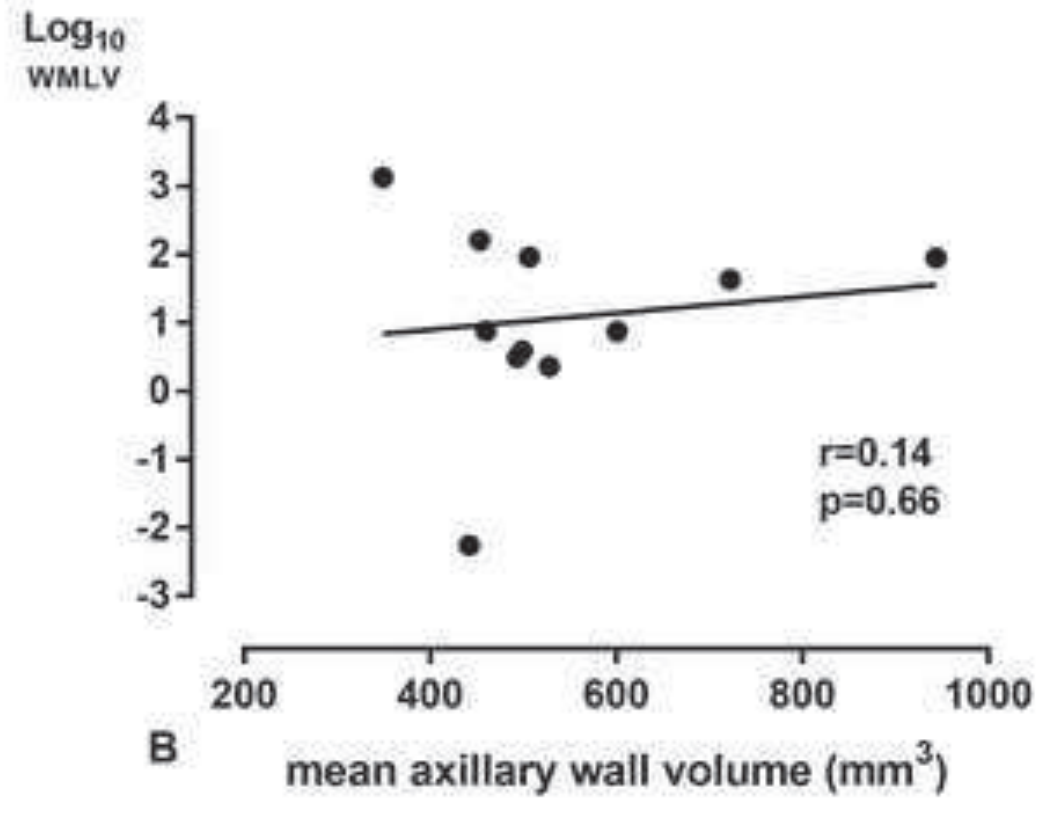

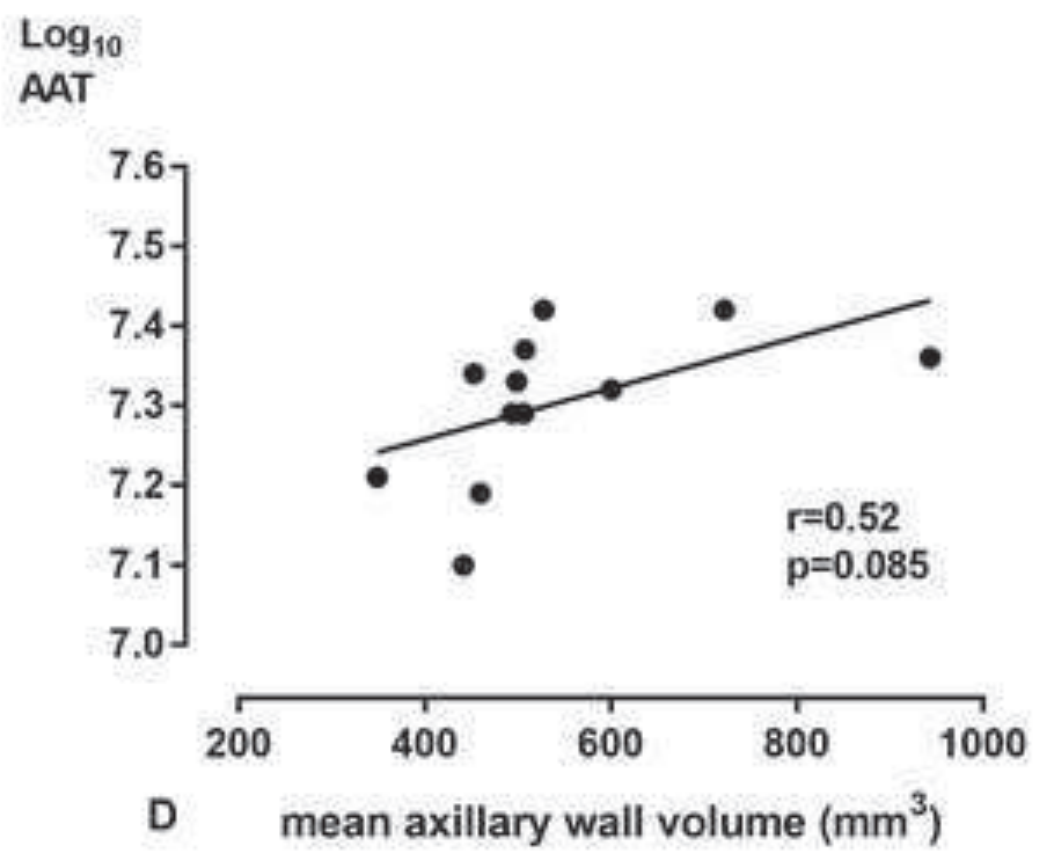

